\title{
Review: limited data on dietary treatment of type 2 diabetes show that dietary advice plus exercise appears more beneficial than dietary advice alone
}

Moore H, Summerbell C, Hooper L, et al. Dietary advice for treatment of type 2 diabetes mellitus in adults. Cochrane Database Syst Rev 2004;(2):CD004097.

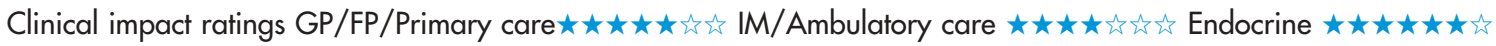

In adults with type 2 diabetes mellitus, what is the effect of different types of dietary advice?

\section{METHODS}

Data sources: Medline (1966 to October 2003), CINAHL (1982
to October 2003), EMBASE/Excerpta Medica (1980 to October
2003), Cochrane Library (Issue 3, 2003), AMED (1985 to
October 2003), bibliographies of relevant articles, and expert
contact.
Study selection and assessment: randomised controlled trials
(RCTs) in any language of $\geqslant 6$ months' duration in which dietary
advice was the main intervention in adults aged $\geqslant 18$ years with
type 2 diabetes. Studies of patients with impaired glucose
tolerance, acute illness, or pregnancy or of the effects of
medication, fish oils, supplementation, or Chinese medical herbs
were excluded. Studies were assessed by 2 independent
reviewers for design, allocation concealment, blinding of
outcome assessment, and description of dropouts and
withdrawals.
Outcomes: weight, diabetic control measures, morbidity
(microvascular or macrovascular diabetic complications), total
mortality, and quality of life.

\section{MAIN RESULTS}

18 RCTs ( 1467 patients; 743 patients in intervention groups and 724 in control groups) met the selection criteria. All included RCTs were of limited methodological quality.

Of 9 RCTs that examined the effects of 2 types of dietary advice (that did not differ in intent to lose weight), 2 RCTs compared an American Diabetes Association exchange diet with a standard reduced fat diet, 5 compared low fat with moderate fat or low carbohydrate diets, and 2 compared very low calorie diets with low calorie diets. RCTs were not pooled because 3 did not provide adequate data. The other RCTs did not provide enough data to reach any substantial conclusions about the effects of the 2 types of dietary advice.

6 RCTs reported that dietary advice plus exercise was associated with greater decreases in mean weight and in mean glycated haemoglobin than dietary advice alone (table). However, the effect on weight was overestimated by the imbalance in baseline weights between groups in I RCT.

3 RCTs examined dietary advice plus behavioural approaches versus dietary advice alone. The authors did not pool these RCTs because 1 did not provide adequate data to allow for pooling. The other RCTs did not provide enough data to reach any substantial conclusions about the effects of dietary advice plus behavioural approaches versus dietary advice alone.

\section{CONCLUSIONS}

Data are limited on the effectiveness of dietary treatment of type 2 diabetes mellitus. Exercise as an adjunct to dietary advice appears to improve glycosylated haemoglobin levels more than dietary advice alone.

For correspondence: Miss $\mathrm{H}$ Moore, University of Teesside, Middlesbrough, UK. H.moore@tees.ac.uk

Source of funding: not stated
Dietary advice plus exercise $v$ dietary advice alone*

\begin{tabular}{lll}
\hline Outcomes & $\begin{array}{l}\text { Number of studies } \\
\text { (number of patients) }\end{array}$ & $\begin{array}{l}\text { Weighted mean difference } \\
(95 \% \mathrm{Cl})\end{array}$ \\
\hline $\begin{array}{l}\mathrm{HbA_{1c }}(\%) \\
\text { at } 6 \text { months }\end{array}$ & $4(227)$ & $-0.86(-1.33$ to -0.38$)$ \\
$\begin{array}{l}\mathrm{Hb} \mathrm{A}_{1 \mathrm{c}}(\%) \\
\text { at } 12 \text { months }\end{array}$ & $3(132)$ & $-0.96(-1.53$ to -0.39$)$ \\
\hline
\end{tabular}

${ }^{*} \mathrm{HbA} \mathrm{Ic}_{\mathrm{c}}=$ glycosylated haemoglobin; $\mathrm{Cl}$ defined in glossary. A fixed effects model was used.

\section{Commentary}

$\mathrm{D}$ espite numerous publications about dietary interventions in diabetes, the number of RCTs is limited, the intervention effect is variable and small, the measures of the fidelity with which the intervention was delivered are often lacking, and the amount of contact time between investigators and participants in intervention and control groups is not reported. Most studies do not provide enough details to enable assessment of how these interventions can be implemented in the primary care of patients with diabetes. No trials compare (1) dietary restrictions with no dietary restrictions or (2) regimens aimed at weight loss with regimens aimed at improving or maintaining metabolic control. One is left to extrapolate the pooled reduction in haemoglobin $(\mathrm{Hb}) \mathrm{A}_{1 \mathrm{c}}$ (by approximately $1 \%$ with diet and exercise $v$ diet alone) to the reductions in risk of death $(25 \%)$, myocardial infarction $(15 \%)$, and microvascular complications (35\%) measured in the observational component of the UK Prospective Diabetes Study. ${ }^{1}$

The weak finding of a beneficial effect of adding exercise to diet on $\mathrm{HbA}_{1 c}$ after 12 months of intervention is consistent with currently available evidence in populations who are at risk of diabetes (such as the Diabetes Prevention Program) ${ }^{2}$ and recommendations of the American Diabetes Association. ${ }^{3}$ Thus, although multifaceted interventions including lifestyle changes appear to be effective in the short term, ${ }^{4}$ the effect on long term micro and macrovascular outcomes is still unknown. ${ }^{5}$

Gunjan Y Gandhi, MD Steven A Smith, MD Mayo Clinic

Rochester, Minnesota, USA

1 Stratton IM, Adler Al, Neil HA, et al. Association of glycaemia with macrovascular and microvascular complications of type 2 diabetes (UKPDS 35): prospective observational study. BMJ 2000;321:405-12.

2 Knowler WC, Barrett-Connor E, Fowler SE, et al. Reduction in the incidence of type 2 diabetes with lifestyle intervention or metformin. N Engl J Med 2002;346:393-403.

3 Franz MJ, Bantle JP, Beebe CA, et al; American Diabetes Association. Nutrition principles and recommendations in diabetes. Diabetes Care 2004;27 Suppl 1:S36-46.

4 Norris SL, Engelgau MM, Narayan KM. Effectiveness of self-management training in type 2 diabetes: a systematic review of randomized controlled trials. Diabetes Care 2001;24:561-87.

5 Ryan DH, Espeland MA, Foster GD, et al. Look AHEAD (Action for Health in Diabetes): design and methods for a clinical trial of weight loss for the prevention of cardiovascular disease in type 2 diabetes. Control Clin Trials 2003;24:610-28. 